\title{
Proposta de um Repositório de Conhecimentos em Governança de TIC
}

\author{
Gabriel Ulian Briganó ${ }^{1}$, Jacques Duílio Brancher ${ }^{1}$, Rodolfo Miranda de Barros ${ }^{1}$ \\ ${ }^{1}$ Departamento de Computação - Universidade Estadual de Londrina (UEL) \\ Londrina, PR - Brasil \\ gabrielbrigano@gmail.com, \{jacques, rodolfo\}@uel.br
}

\begin{abstract}
This paper brings a proposal for a repository of knowledge in information technology and communication governance whose main objectives is makes it closer to the managers, organizing and controlling its development in organizations, and providing information to conduct research and development scientific studies. The repository was proved be very effective, achieving satisfactory results, like deploying of a helpdesk solution in the department of Computing at State University of Londrina. With the application of a process of analysis, the repository suggests ways to organizations obtains a good development of their ITC governance in a short time, this makes it's a useful and powerful tool.
\end{abstract}

Resumo. O presente artigo propõe um repositório de conhecimentos em governança de TIC, que tem como principais objetivos torna-la mais próxima aos empresários, organizando e controlando o seu desenvolvimento nas organizações, e também, fornecendo informações para pesquisas e desenvolvimento de estudos na área. O repositório tem se mostrado muito eficiente, alcançando resultados satisfatórios, como no caso da implantação de um service desk no departamento de computação da Universidade Estadual de Londrina. A partir da aplicação de um processo de análise, o repositório sugere meios para as organizações obterem um melhor desenvolvimento de sua governança de TIC, isto faz dele uma ferramenta muito útil e poderosa.

\section{Introdução}

No atual cenário econômico competitivo as empresas são cada vez mais dependentes da TIC para tomarem decisões acertadas em tempos cada vez menores. Para isso, elas devem se organizar e desenvolvê-la de modo controlado, definido e em alinhamento com os objetivos de negócio, para tal, faz-se uso da governança de TIC [Lunardi 2010].

Devido a esta dependência e necessidade das informações sobre a organização e de um gerenciamento correto, pode ser imprescindível a utilização de ferramentas, técnicas e metodologias que auxiliem as organizações no controle e direcionamento de sua TIC, fazendo, assim, com que esta seja alinhada aos seus objetivos e retorne valor para o negócio.

Constata-se que as ferramentas, técnicas e metodologias possuem características específicas e encontram-se, de maneira geral, em lugares distintos e isolados. Este fato faz com que as organizações gastem muito tempo na busca de alguma solução que possa atendê-la de modo satisfatório como também na capacitação e implantação da mesma. 
Além disso, um repositório de conhecimentos em TIC visa fornecer as tecnologias, ferramentas, metodologias e demais ativos que possam auxiliar as organizações na obtenção de um melhor controle e gerenciamento de suas informações em um único local de maneira integrada. Provendo, dessa forma, uma base diversificada e funcional.

Baseando-se nisto, e com o objetivo de auxiliar as empresas a conseguirem melhores resultados com sua TIC, estudos neste sentido vêm sendo desenvolvidos desde 2008, juntamente com empresas da região, visando à elaboração de meios para melhorar as condições das mesmas.

Este repositório está contido em um framework que aborda todo um processo de melhoria, desde a identificação de problemas relacionados à TIC até a aplicação de soluções e coleta de lições aprendidas. Ele desempenha um papel fundamental, e sua função, além de oferecer uma base viva de soluções, é relacionar os problemas encontrados com as soluções sugeridas e os resultados obtidos. Possibilitando, assim, a mensuração das soluções e do framework de maneira geral.

O objetivo do presente trabalho é apresentar o Repositório de Conhecimentos proposto, bem como de seu relacionamento e integração com o framework. Para este fim, o mesmo está dividido da seguinte forma: Seção 2, revisão dos conceitos motivadores a para a existência e evolução. Seção 3, exibição como o projeto surgiu e se evoluiu. Seção 4, descrição da proposta do presente artigo, suas características e funcionamento. Seção 6, exibição dos resultados obtidos até o presente momento e, por fim, a conclusão do trabalho.

\section{Revisão conceitual}

O processo de criação de um Repositório de Conhecimentos exige uma junção de diferentes saberes e conceitos. Dentre os que balizam o trabalho em questão, pode-se citar a própria governança de TIC, o ITIL, que por meio de seus processos puderam construir e manter o repositório de forma organizada. E o CobIT, que por meio de seus processos e indicadores foi crucial para a determinação dos conteúdos.

\subsection{Governança de TIC}

A tecnologia de informação é um componente essencial no meio empresarial, e as empresas a têm utilizado ampla e intensamente, tanto em nível estratégico como operacional. Isso faz com que ela seja vista não apenas como uma tecnologia de suporte às organizações, mas que assuma um papel estratégico no cenário organizacional [Albertin 2008].

Dessa forma, e a governança de TIC possui alguns propósitos, descritos abaixo: [ITGI 2012]

- Alinhar a TIC com a organização e alcançar os benefícios esperados.

- Utilizar a TIC para permitir que a organização explore melhor as oportunidades e maximize os benefícios.

- Utilizar os recursos de TIC com responsabilidade.

- Gerenciar os riscos relacionados à TIC, apropriadamente. 
Tais propósitos não são triviais nem tão pouco fáceis de serem alcançados, dessa maneira a governança é o maior motivador de todo o trabalho, que tem por objetivo principal facilitar o aprendizado da mesma e a aplicação de meios para que seu uso seja correto e apoie a organização na obtenção de seus objetivos.

\subsection{ITIL e CobIT}

O ITIL é uma biblioteca de boas e melhores práticas para o gerenciamento de serviços de TIC, elaborado pelo governo britânico como meio de garantir a qualidade de seus serviços prestados e consumidos. Ele aborda os serviços de TIC durante todo seu ciclo de vida e sugere cinco fases, contendo diversos mecanismos, para que o gerenciamento seja realizado de maneira adequada em todas as suas fases [ITSMF 2009].

CobIT (Control Objectives for Information \& related Technology) é uma ferramenta para auxiliar os gerentes de negócio a compreender e gerenciar os riscos associados à implementação de novas tecnologias, e demonstrar para executivos, acionistas e demais stakeholders como e quão bem isto é realizado. Ele é baseado em melhores práticas de gerenciamento de controle de TIC, consolidadas internacionalmente [Fagundes 2009].

\section{GERTI}

Em 2008, foi criado, na Universidade Estadual de Londrina o projeto de extensão universitária, intitulado "Gerenciamento de Serviços de TI no Pólo Moveleiro de Arapongas". O projeto foi concebido a partir da necessidade da região, com o objetivo de auxiliar as empresas produtoras de móveis a gerirem seus ativos, melhorarem seus investimentos sobre TIC e auxiliá-las com o gerenciamento de seus serviços internos e com a gestão das informações.

Assim, as atividades foram desenvolvidas, de modo a elaborar um repositório de soluções de TIC. Inicialmente, este continha apenas estudos analíticos de ferramentas livres que auxiliam no gerenciamento de serviços e na gestão de informação. Com o tempo, expandiu-se, passando a oferecer um método de avaliação da implementação da governança TIC em organizações e de seu relacionamento com os objetivos estratégicos das organizações [Briganó e Barros 2010], conforme Figura 1.

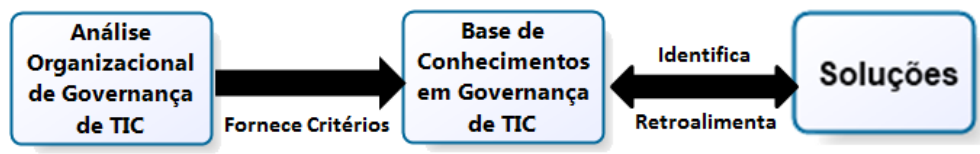

Figura 1. Visão macro do Framework GERTI.

A figura 1 traz um diagrama de todo o framework como também destaca o enquadramento do repositório de conhecimentos, dessa maneira, tem-se a seguinte estrutura: Inicialmente realiza-se uma análise, que tem como resultado informações sobre os aspectos organizacionais e problemas, pontos fracos e de melhoria relacionados à TIC. Em um segundo momento, os itens contidos no repositório são utilizados para se encontrar soluções aplicáveis à organização em questão. Estas soluções, por sua vez, após serem aplicadas, retroalimentam o repositório por meio de lições aprendidas. 


\section{Repositório de Conhecimentos}

O repositório de conhecimentos proposto, denominado base de conhecimentos em governança de TIC na Figura 1, compreende os conhecimentos adquiridos em governança de TIC e as lições aprendidas, resultantes da aplicação destes.

Inicialmente, contendo apenas análises de ferramentas, as sugestões de soluções se resumiam apenas à implantação das mesmas e as lições aprendidas eram retiradas de todo este processo. Dessa maneira, já naquele momento, foi constatada a necessidade de aplicação de treinamentos para os usuários e operadores das ferramentas. Percebeu-se que o repositório teria um processo evolutivo intenso e que as lições aprendidas seria o ponto chave para viabilizar as evoluções.

Pode-se dizer que evolução do repositório consiste, atualmente, em mais estudos de casos, processos, normas, metodologias, modelos, guias, tutoriais, treinamentos, melhores práticas e lições aprendidas, conforme Figura 2.

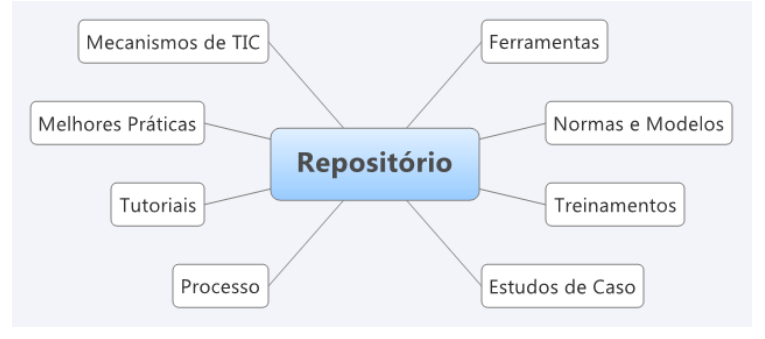

Figura 2. Estrutura do Repositório.

A figura 2 exibe o conteúdo do repositório, representado pelos quadros e pelas linhas pontilhadas respectivamente. Embora, cada item contido no repositório se defina isoladamente, podendo ser por si só uma solução, eles podem ser combinados de forma a atender as necessidades da organização. Além disso, todos possuem relação com as lições aprendidas, estas, por sua vez, podem resultar da aplicação de qualquer solução, seja ela composta por um ou vários itens combinados.

O repositório, também, conta com a biblioteca ITIL, CobIT e materiais auxiliares para a compreensão dos mesmos. Tais itens alicerçaram o repositório e foram fundamentais para o desenvolvimento e evolução do mesmo. Em um nível mais aprofundado cada item contido no repositório possui informações específicas, que o classificam, relacionam com problemas, descrevem e facilitam a utilização.

\section{Resultados obtidos a partir do repositório.}

O repositório proposto, neste artigo, foi aplicado em diversos casos, tanto na academia quanto nas empresas, obtendo-se muitos resultados positivos, tais como, oportunidades de pesquisa e produção de novos trabalhos e melhora na gestão da TIC e no manejo de informações, respectivamente. Tais resultados realimentaram o repositório, possibilitando sua evolução. Como exemplo, pode-se citar:

Caso 1: Implantação de um service desk no departamento de computação: Conforme descrito no estudo de caso "A Implantação de um Service Desk: Um Estudo de Caso Aplicando Conceitos do ITIL e do PMBOK” [Briganó e Barros 2011], foi implantada no departamento de computação da Universidade Estadual de Londrina uma solução de Service Desk. 
Tal solução alcançou benefícios significativos para o departamento, tais como: a quantificação dos serviços prestados, mapeamento das naturezas dos serviços, determinação do tempo médio, capacidade de atendimento, melhor organização e gerenciamento dos chamados segundo a prioridade e técnicos disponíveis.

Caso 2: Realização de um estudo sobre ITIL e PMBOK, comparando as duas metodologias e identificando os pontos de complementariedade entre elas. Este trabalho culminou com a criação de uma empresa fictícia com alguns problemas de TIC e a apresentação das soluções dos mesmos. Estas seguiram o modelo de ciclo de vida do ITIL e podem ser consultadas em [Gili 2009].

Caso 3: Realização de um estudo sobre a ISO 27000 e o ITIL, este trabalho, também, culminou com o estudo de caso de uma empresa fictícia com problemas de segurança de informação. No qual foram apresentadas soluções, conforme o ciclo de vida do ITIL [Luna 2010].

Caso 4: Desenvolvimento de uma metodologia para análise da TIC nas empresas: Foi desenvolvida uma metodologia para a realização de uma análise automatizada dos objetivos de negócio e ativos de TIC [Briganó e Barros 2010].

Além destes resultados, foram criadas oportunidades para academia, no que diz respeito ao desenvolvimento de outros estudos de caso, pesquisas e análise com os dados coletados através das lições aprendidas e novas metodologias para melhorar a governança de TIC nas organizações. Simultaneamente, as empresas regionais se beneficiam com as soluções sugeridas pelo repositório e com acesso rápido as tendências de TIC do mercado.

\section{Conclusão}

A aplicação do repositório em ambientes acadêmicos e empresariais mostrou-se um sucesso, agregando valor para ambos os lados, pois possibilita o desenvolvimento de novas pesquisas e fornece informações para estudos e análises no que diz respeito à governança de TIC e seus mecanismos no meio acadêmico. No meio corporativo, fornece apoio para as empresas que desejam amadurecer sua governança, oferecendo soluções em um tempo menor e de forma mais assertiva que as iniciativas particulares e pontuais das empresas.

Também, com a utilização das lições aprendidas é possível acompanhar os resultados das soluções aplicadas e, a partir deles, incorporar novos itens ao repositório e/ou melhorar os já existentes, de forma a mantê-lo sempre vivo e adequado às mudanças de cenário empresarial.

\section{References}

Albertin, A. L. (2008), "Albertin, R. M. de M., Benefícios do uso da tecnologia de informação para o desempenho empresarial", Revista de Administração Pública, Mar/Abr 2008, FGV, Rio de Janeiro, Brasil, p. 275 - 302.

Briganó, U. G. e Barros, R. M. (2010), “A Implantação de um Service Desk: Um Estudo de Caso Aplicando Conceitos do ITIL e do PMBOK", XXXVIII Congresso Brasileiro de Educação em Engenharia - COBENGE 2010, Brasil. 
Briganó, U. G. e Barros, R. M. (2011), “Aprendizado de TI: Um modelo para melhorar o aprendizado de TI nas organizações", VII Congresso Brasileiro de Sistemas de Informação - SBSI 2011, Salvador, Brasil.

Fagundes, E. M. (2009). "CobIT - Um kit de ferramentas para gestão de TI". Disponível em: http:/www.efagundes.com/Artigos/COBIT.htm. Acesso em: 11/02/11.

Gili, P. Diogo (2009). “Um Estudo de PMBOK® e ITIL®.”. Trabalho de Conclusão de Curso. Universidade Estadual de Londrina. Brasil.

ITGI - Information Technology Institute - www.itgi.org - acessado em Janeiro de 2012.

ITSMF.: ITIL v3 - Introduction to official Service Life-Cycle, (2007)

Luna, M. (2010). "Gestão da segurança da Informação com ITIL V3 e ISO 27002". Trabalho de Conclusão de Curso. Universidade Estadual de Londrina. Brasil.

Lunardi, G. L., Becker, J. L., Maçada, A. C. G. (2010), "Impacto da Adoção de Mecanismos de Governança de Tecnologia da Informação (TI) no desempenho da Gestão da TI: uma análise baseada na percepção dos executivos", Revista de Ciências da Administração, v. 12, n. 28, p. 11-39, set/dez 2010. 